\title{
Forças de caráter envolvidas na prática docente: As perspectivas do professor
}

\author{
Character strengths involved in teaching practice: The teacher's perspectives \\ Fortalezas del carácter involucradas em la práctica docente: Las perspectivas del professor
}

Recebido: 23/05/2021 | Revisado: 29/05/2021 | Aceito: 01/06/2021 | Publicado: 14/06/2021

\author{
Iracema Mirella Alves Lima Nascimento \\ ORCID: https://orcid.org/0000-0002-5520-8162 \\ Universidade de Pernambuco, Brasil \\ E-mail: mirellaalima@hotmail.com \\ José Antônio Spencer Hartmann Júnior \\ ORCID: https://orcid.org/0000-0002-6799-2599 \\ Universidade de Pernambuco, Brasil \\ E-mail: jose_spencer@yahoo.com.br
}

\begin{abstract}
Resumo
O estudo das forças pessoais é um dos constructos da psicologia positiva e seus fundamentos podem ser utilizados com ferramentas para o aperfeiçoamento da prática docente. Diante disso, este estudo buscou investigar, a partir do ponto de vista dos professores, quais forças de caráter são consideradas importantes para sua prática profissional. Trata-se de um estudo exploratório de abordagem quantitativa. Participaram 82 docentes de uma instituição pública de educação que lecionavam em diferentes níveis de ensino, no nordeste brasileiro, $61 \%$ eram do sexo feminino, $41,5 \%$ tinham em média de 30 alunos por turma. Como instrumentos de coleta de dados, utilizou- se um questionário com características pessoais, profissionais e de saúde e uma indagação: acerca das forças de caráter, qual você considera mais importante para o exercício da docência?. Os dados foram coletados por meio de formulário eletrônico, google form (®. A análise de dados ocorreu através do software SPSS, versão 21. Os resultados revelaram que, para os professores, as forças de caráter mais importantes para exercer a docência são: inteligência social, cidadania, amor por aprender, criatividade, amor, integridade, mente aberta, esperança, persistência, curiosidade, equidade, humildade e liderança. Ocorreram associações significativas entre a importância da inteligência social e o sexo, como também entre a importância do exercício da cidadania e o número médio de alunos por turma. Revelou-se uma maior ênfase na natureza humana do processo de ensino e aprendizagem.
\end{abstract}

Palavras-chave: Psicologia positiva; Docentes; Assistência em saúde mental; Desenvolvimento de pessoal.

\begin{abstract}
The study of personal strengths is one of the constructs of positive psychology and its foundations can be used as tools for the improvement of teaching practice. Therefore, this study sought to investigate, from the teachers' point of view, which character forces are considered important for their professional practice. This is an exploratory study with a quantitative approach. 82 teachers from a public educational institution who taught at different levels of education participated, in northeastern Brazil, 61\% were female, $41.5 \%$ had an average of 30 students per class. As a data collection instrument, we used a questionnaire with personal, professional and health characteristics and a question: about character strengths, which do you consider the most important for the exercise of teaching?. Data were collected using an electronic form, google form ®. Data analysis was performed using SPSS software, version 21 . The results revealed that, for teachers, the most important character forces for teaching are: social intelligence, citizenship, love for learning, creativity, love, integrity, mind open, hope, persistence, curiosity, equity, humility and leadership. There were significant associations between the importance of social intelligence and sex, as well as between the importance of exercising citizenship and the average number of students per class. There was a greater emphasis on the human nature of the teaching and learning process.
\end{abstract}

Keywords: Psychology positive; Teaching work; Teacher characteristics; Personal growth techniques.

\section{Resumen}

El estudio de las fortalezas personales es uno de los constructos de la psicología positiva y sus fundamentos pueden utilizarse como herramientas para mejorar la práctica docente. Por lo tanto, este estudio buscó investigar, desde el punto de vista de los docentes, qué fuerzas de carácter se consideran importantes para su práctica profesional. Se trata de un estudio exploratorio con enfoque cuantitativo. Participaron 82 docentes de una institución educativa pública que impartían clases en diferentes niveles de educación, en el noreste de Brasil, 61\% eran mujeres, 41,5\% tenían un promedio de 30 alumnos por clase. Como instrumento de recogida de datos se utilizó un cuestionario con características personales, profesionales y de salud y una pregunta: sobre las fortalezas de carácter, ¿cuáles consideras más importantes para el ejercicio de la docencia ?. Los datos fueron recolectados a través de un formulario

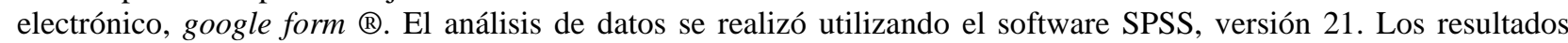


revelaron que, para los maestros, las fuerzas de carácter más importantes para la enseñanza son: inteligencia social, ciudadanía, amor por aprender, creatividad, amor, integridad, mente abierta, esperanza, persistencia, curiosidad, equidad, humildad y liderazgo. Hubo asociaciones significativas entre la importancia de la inteligencia social y el sexo, así como entre la importancia de ejercer la ciudadanía y el número promedio de estudiantes por clase. Se hizo mayor hincapié en la naturaleza humana del proceso de enseñanza y aprendizaje.

Palabras clave: Psicología positiva; Docentes; Atención a la salud mental; Desarrollo de personal.

\section{Introdução}

Mesmo diante de controvérsias quanto ao início das pesquisas relacionadas à Psicologia positiva, acredita- se que este movimento teve início em 1998, quando Martin Seligman assumiu a presidência da American Psychological Association (APA) e, em 2000, quando no intuito de mostrar as evidências científicas acerca dessa temática, Seligman e Czikszentmihalyi publicaram uma edição especial da American Psychologist (Paludo\&Koller, 2007).

Na publicação, "Positive Psychology: na introdution”, Seligman e Csikszentmihalyi, em 2000, apontaram que, desde a Segunda Guerra Mundial, a psicologia dedicou- se, quase que exclusivamente, aos estudos voltados para doenças, uma vertente curativista. Eles mostraram a necessidade de busca de outras perspectivas, notoriamente de aspectos positivos, que poderão levar à compreensão de como funcionam os fatores que permitem que indivíduos, comunidades e sociedades floresçam.

Diante disso, conclui- se que a Psicologia Positiva apresenta uma proposta de ampliação de conhecimentos e consequentemente mudar o foco nas doenças, e seus efeitos de causa e consequência, outrossim objetiva compreender o comportamento humano, com o intuito de valorizar suas potencialidades, trabalhando as habilidades socioemocionais, o que se apresenta fundamental para a saúde mental dos indivíduos (Oliveira, 2021).

Os embasamentos teóricos desta vertente buscam trabalhar as forças humanas com o intuito de compreendê- las e promove-las, além de propor- se a desenvolver qualidades que colaborem para o florescimento individual e coletivo. A partir desses estudos, será possível contribuir com estratégias de prevenção em saúde mental, que, provavelmente, será o objetivo das ações neste século (Seligman \& Csikszentmihalyi, 2000).

E, no intuito de estruturar este modelo teórico, considera- se três pilares fundamentais, embasados em pesquisas com rigor metodológico científico: a emoção positiva; estudo de traços positivos, ligados às características e ao funcionamento de cada indivíduo, especialmente forças pessoais e virtudes; e as instituições positivas, relacionados às virtudes cívicas e instituições que apoiam as virtudes e emoções positivas dos indivíduos (Seligman, 2019).

Em se tratando dos estudos que investigam os aspectos do funcionamento humano, considera- se que as forças de caráter são traços positivos que refletem no desenvolvimento de pensamentos, sentimentos e comportamentos que favoreçam o crescimento da pessoa. Desta maneira, essas características existem em diferentes níveis e podem ser medidas como diferenças próprias (Park, Peterson \& Seligman, 2004).

Destarte, constata- se que o conceito desse constructo é um dos elementos fundamentais da psicologia positiva, sendo que o bom caráter pode e deve ser cultivado (Peterson \& Seligman, 2004). Verifica- se que o exercício frequente dessas forças propicia o desenvolvimento de sentimentos positivos e, consequentemente, qualidade de vida, vida imbuída de autenticidade, melhores relacionamentos e, através disso, promove- se o bem-estar subjetivo (Seligman, 2019).

Desta maneira, embasados em diversos estudos, como escritos filosóficos, teorias da psicologia, religiões em diferentes culturas, Peterson e Seligman (2004) elaboraram um manual em que descrevem as 6 (seis) virtudes humanas e as 24 (vinte e quatro) forças de caráter.

Em se tratando da virtude da sabedoria, a mesma pode ser alcançada pelo exercício das forças de caráter criatividade, curiosidade, mente aberta, amor por aprender, perspectiva; já a virtude da coragem envolve as forças de caráter, bravura, persistência, integridade, vitalidade; enquanto a virtude humanidade engloba as forças amor, bondade, inteligência social; 
quanto a virtude justiça, é alcançada por meio das forças liderança, exercício da cidadania e equidade; em se tratando da virtude temperança, encontram- se as forças de caráter perdão, humildade, prudência e autocontrole; e, por fim, a virtude transcendência, constituída das forças de caráter apreciação da beleza e da excelência, gratidão, esperança, humor e espiritualidade (Peterson \& Seligman, 2004).

Em pesquisa brasileira, realizada por Oliveira, Nunes, Legal e Noronha (2016), constatou - se que as forças de caráter se relacionam significativamente com o aumento dos afetos positivos, em contrapartida, não apresentou correlação com a diminuição dos afetos negativos. Desta maneira, os autores concluíram que as forças de caráter estão relacionadas mais fortemente ao parâmetro emocional do bem-estar subjetivo, mais especificamente com os afetos positivos e menos relacionada com seu componente cognitivo, a satisfação de vida.

Deste modo, conhecer e cultivar as forças de caráter precisam constituir a formação de toda criatura humana. Através deste desenvolvimento, a pessoa poderá dar um maior sentido à vida, de maneira que aprenderá a valorizar as próprias experiências e as dos outros (Ribeiro, 2018).

E, um ambiente favorável para o desenvolvimento destas virtudes e forças de caráter é o escolar. As práticas realizadas nesta esfera podem contribuir com o crescimento de todos os sujeitos que compõem o contexto acadêmico, entre eles, o professor, elemento chave no processo de ensino - aprendizagem.

Estudo brasileiro realizado por Cacciari (2015), com professores universitários, relacionou as forças de caráter à satisfação com a vida e bem-estar afetivo no trabalho. Seus resultados mostraram que os docentes indicaram a virtude da sabedoria como importante para o trabalho do professor. Além disso, esses participantes apontaram possuir as virtudes coragem e temperança, que apresentaram correlação direta com a satisfação com a vida e com afetos positivos vivenciados no trabalho.

De acordo com Ferreira (2018), a aplicabilidade da psicologia positiva no ambiente escolar justifica-se não apenas por deixar os estudantes mais felizes, mas também por auxiliar o relacionamento entre os professores e toda a equipe escolar. Isto traz consequências diretas no bem-estar dos educadores e menor desgaste na prática da ação docente.

Por conseguinte, considerando o papel do professor no contexto escolar é crucial compreender de que maneira este público vivencia a educação (Cintra, 2016). Pesquisas mostram que a relação aluno-professor influencia significativamente na percepção de sucesso, prazer pela escola, e bem-estar dos estudantes. Diante disso, verifica- se a relevância tanto do bem-estar dos alunos como do bem- estar dos próprios professores (Gaspar et al., 2020; Tomé et al., 2017).

No âmbito do reconhecimento dessas habilidades no contexto escolar, em pesquisa conduzida por Cacciari (2015), os professores participantes informaram que as características de um docente ideal estão ancoradas nas seguintes virtudes: conhecimento, temperança, justiça e humanidade. E, com relação as virtudes utilizadas por eles próprios, os participantes descreveram: temperança, transcendência e humanidade. Sendo que a virtude humanidade se apresenta entre as necessárias e utilizadas.

Diante da literatura apresentada, verifica- se a importância de conhecer quais as forças de caráter consideradas mais importantes para o exercício da docência, sob a ótica do próprio educador. A partir deste reconhecimento, as instituições poderão investir em programas de intervenção fundamentados nesses conceitos apresentados, que poderão contribuir com a saúde mental e o aperfeiçoamento das práticas desses profissionais, o que traz consequências diretas ao processo de ensinoaprendizagem. Portanto, o presente estudo buscou investigar, a partir do ponto de vista docente, quais forças de caráter são consideradas importantes para prática profissional de professores. 


\section{Metodologia}

\subsection{Desenho do estudo}

Trata- se de um trabalho de natureza quantitativa, acerca das forças de caráter consideradas mais importantes para o exercício docente.

\subsection{Participantes}

A população desse estudo foi composta por 95 docentes dos diferentes cursos e níveis de ensino, de um dos campi de uma instituição pública educacional de Pernambuco. Aceitaram participar da pesquisa 82 professores, de acordo com o cálculo amostral, o número de participantes superou o número suficiente. Foram incluídos na pesquisa os professores que atuavam na instituição em que a pesquisa foi realizada e excluídos aqueles que estavam afastados de suas atividades no trabalho por um período maior que 2 anos, no período de coleta de dados.

\subsection{Instrumentos}

Para os dados contemplados neste artigo, foram utilizados dois instrumentos:

Questionário com informações acerca do perfil sociodemográfico, ocupacional e de saúde: sexo, idade, escolaridade, número de filhos, estado civil, possuía alguma religião/crença/doutrina, se sim, qual delas; em quantas escolas trabalhava, número de turmas, número de alunos por turma, tempo de exercício na profissão, carga horária semanal de trabalho, realizava atividades de trabalho em outro local que não fosse a escola; exercia outra atividade trabalhista além de professor; histórico de afastamento das atividades por motivo de saúde por causas relacionadas à transtornos mentais.

Resolução do seguinte questionamento: "Entre as 24 (vinte e quatro) forças de caráter apresentadas, qual você considera mais importante para o exercício da docência?".

\subsection{Procedimentos para coleta de dados}

Os dados foram coletados no período de 18 de julho a 18 de agosto de 2020. Devido às recomendações de isolamento social, impostos pela pandemia covid- 19, a coleta de dados foi realizada por meio da utilização do Google form ®.

Os professores foram convidados a participar da pesquisa através do e-mail institucional, onde recebiam o formulário eletrônico. Na oportunidade, acessavam o Termo de Consentimento Livre e Esclarecido. Em caso de aceite, eram direcionados aos questionários. Os que não aceitavam, eram encaminhados a uma página de agradecimento.

Esta pesquisa foi submetida ao Comitê de Ética em Pesquisa via Plataforma Brasil. Logo, todos os preceitos éticos foram garantidos, de modo a permitir a ciência dos participantes quanto aos objetivos da pesquisa, os riscos e os benefícios a que estavam sendo submetidos, bem como quanto ao caráter voluntário da sua participação, sigilo e confidencialidade dos dados.

\subsection{Análise de dados}

Para análise dos dados, foi construído e validado um banco de dados na planilha eletrônica Microsoft Excel que posteriormente foi exportado para o software SPSS, versão 21, onde foi realizada a análise. Para avaliar o perfil dos docentes e as características de estudo, foram calculadas as frequências percentuais e construídas as respectivas distribuições de frequências das variáveis quantitativas (Mesquita, Branco \& Soares, 2013).

Foi verificada a normalidade dos escore padronizado pelo teste de Kolmogorov-Smirnov. Foram aplicados o teste Qui-quadrado para comparação de proporção na comparação dos percentuais das categorias das variáveis do estudo, o teste de Kolmogorov-Smirnov para avaliar a normalidade dos escore padronizado (Mesquita, Branco \& Soares, 2013) e, ainda, o teste 
Exato de Fisher que analisa a significância estatística (Agresti, 1992). Todas as conclusões foram tiradas considerando o nível de significância de $5 \%$.

\subsection{Aspectos éticos}

Todos os aspectos éticos foram respeitados, sendo que os dados foram coletados após aprovação do Comitê de ética e pesquisa com animais e seres humanos. Todos os participantes da pesquisa assinaram o Termo de Consentimento Livre e Esclarecido.

\section{Resultados}

Participaram do estudo 82 docentes, sendo que $61 \%$ eram do sexo feminino, casado ou em união estável $(75,6 \%)$, não possuía filho (36,6\%), tinha religião (82,9\%), a média da idade dos professores é de 41,3 anos com desvio padrão de 8,8 anos, sendo que o mais novo tinha 28 anos e o mais velho 65 anos de idade.

Quanto as características profissionais, o perfil do público analisado apresentou as seguintes características: 95, 1\% dos docentes trabalhava em uma escola, 40,2\% lecionava em 3 a 4 turmas, tendo a média de 30 alunos por turma (41,5\%), 73, $7 \%$ atuava no ensino médio técnico, 30,5\% exercia a profissão de docente entre 11 e 20 anos e 42,7\% eram mestres. No âmbito do histórico de transtornos mentais $87,8 \%$.

Os resultados obtidos por meio desta pesquisa evidenciaram a seguinte distribuição das forças de caráter (Tabela 1), consideradas mais importantes pelos docentes para o exercício da sua prática profissional: a inteligência social (32,9\%) e o exercício da cidadania $(18,3 \%)$.

Tabela 1. Distribuição da Força de caráter que considera mais importante.

\begin{tabular}{ccc}
\hline Força de caráter & n & \% \\
\hline Inteligência social & 27 & 32,9 \\
Exercício da cidadania & 15 & 18,3 \\
Amor por aprender & 7 & 8,5 \\
Criatividade & 7 & 8,5 \\
Amor & 6 & 7,3 \\
Integridade & 6 & 7,3 \\
Mente aberta & 4 & 4,9 \\
Esperança & 3 & 3,7 \\
Persistência & 3 & 3,7 \\
Curiosidade & 1 & 1,2 \\
Equidade & 1 & 1,2 \\
Humildade & 1 & 1,2 \\
Liderança & 1 & 1,2 \\
\hline
\end{tabular}

Nota: $\mathrm{n}=$ número de observações; \% = percentual em relação ao total de respostas.

Fonte: Autores.

Juntas, as duas forças de caráter concentram $51,2 \%$ das citações dos docentes participantes. Entre as menos citadas estão: curiosidade, equidade, humildade e liderança (cada uma das últimas, com apenas 1,2\%). Verifica- se ainda que todas as virtudes humanas foram citadas nesta pesquisa, mesmo que indiretamente. 
Diante do elevado número de citações, foram aplicados os testes de comparação entre as características dos docentes participantes com as forças de caráter mais citadas: a inteligência social e o exercício da cidadania, encontrados nas Tabela 2 e Tabela 3.

Tabela 2. Distribuição do uso da força de caráter inteligência social, exercício da cidadania, segundo o perfil pessoal dos professores avaliados.

\begin{tabular}{|c|c|c|c|c|c|}
\hline \multirow{3}{*}{ Fator avaliado } & & \multicolumn{4}{|c|}{ As mais importantes } \\
\hline & & \multicolumn{2}{|c|}{ Inteligência social } & \multicolumn{2}{|c|}{ Exercício da cidadania } \\
\hline & & Sim & Não & Sim & Não \\
\hline \multicolumn{6}{|l|}{ Q1.Sexo } \\
\hline Masculino & & $11(22,0 \%)$ & $39(78,00 \%)$ & $11(22,0 \%)$ & $39(78,0 \%)$ \\
\hline \multirow[t]{2}{*}{ Feminino } & & $16(50,0 \%)$ & $16(50,0 \%)$ & $4(12,5 \%)$ & $28(87,5 \%)$ \\
\hline & p-valor & \multicolumn{2}{|c|}{$0,008^{1}$} & \multicolumn{2}{|c|}{$0,278^{1}$} \\
\hline \multicolumn{6}{|l|}{ Q2.Idade } \\
\hline Até 35 anos & & $7(22,6 \%)$ & $24(77,4 \%)$ & $7(22,6 \%)$ & $24(77,4 \%)$ \\
\hline 36 a 45 anos & & $9(37,5 \%)$ & $15(62,5 \%)$ & $1(4,2 \%)$ & $23(95,8 \%)$ \\
\hline 46 a 59 anos & & $8(34,8 \%)$ & $15(65,2 \%)$ & $7(30,4 \%)$ & $16(69,6 \%)$ \\
\hline \multirow[t]{2}{*}{60 ou mais anos } & & $3(75,0 \%)$ & $1(25,0 \%)$ & $0(0,0 \%)$ & $4(100,0 \%)$ \\
\hline & p-valor & \multicolumn{2}{|c|}{$0,168^{2}$} & \multicolumn{2}{|c|}{$0,076^{2}$} \\
\hline \multicolumn{6}{|l|}{ Q3.Estado civil } \\
\hline Casado/união estável & & $20(32,3 \%)$ & $42(67,7 \%)$ & $9(14,5 \%)$ & $53(85,5 \%)$ \\
\hline Solteiro & & $6(37,5 \%)$ & $10(62,5 \%)$ & $6(37,5 \%)$ & $10(62,5 \%)$ \\
\hline \multirow[t]{2}{*}{ Divorciado } & & $1(25,0 \%)$ & $3(75,0 \%)$ & $0(0,0 \%)$ & $4(100,0 \%)$ \\
\hline & p-valor & \multicolumn{2}{|c|}{$0,906^{2}$} & \multicolumn{2}{|c|}{$0,090^{2}$} \\
\hline \multicolumn{6}{|l|}{ Q4.Número de filhos } \\
\hline Nenhum & & $7(23,3 \%)$ & $23(76,7 \%)$ & $8(26,7 \%)$ & $22(73,3 \%)$ \\
\hline 1 filho & & $7(36,8 \%)$ & $12(63,2 \%)$ & $1(5,3 \%)$ & $18(94,7 \%)$ \\
\hline 2 filhos & & $10(47,6 \%)$ & $11(52,4 \%)$ & $5(23,8 \%)$ & $16(76,2 \%)$ \\
\hline 3 filhos & & $3(42,9 \%)$ & $4(57,1 \%)$ & $1(14,3 \%)$ & $6(85,7 \%)$ \\
\hline \multirow[t]{2}{*}{4 filhos } & & $0(0,0 \%)$ & $5(100,0 \%)$ & $0(0,0 \%)$ & $5(100,0 \%)$ \\
\hline & p-valor & \multicolumn{2}{|c|}{$0,188^{2}$} & \multicolumn{2}{|c|}{$0,286^{2}$} \\
\hline \multicolumn{6}{|l|}{ Q5.Possui religião } \\
\hline Sim & & $23(33,8 \%)$ & $45(66,2 \%)$ & $12(17,6 \%)$ & $56(82,4 \%)$ \\
\hline \multirow[t]{2}{*}{ Não } & & $4(28,6 \%)$ & $10(71,4 \%)$ & $3(21,4 \%)$ & $11(78,6 \%)$ \\
\hline & p-valor & \multicolumn{2}{|c|}{$1,000^{2}$} & \multicolumn{2}{|c|}{$0,714^{2}$} \\
\hline \multicolumn{6}{|l|}{ Q6.Qual religião } \\
\hline Catolicismo & & $13(34,2 \%)$ & $25(65,8 \%)$ & $5(13,2 \%)$ & $33(86,8 \%)$ \\
\hline Evangélico & & $5(35,7 \%)$ & $9(64,3 \%)$ & $2(14,3 \%)$ & $12(85,7 \%)$ \\
\hline Cristianismo & & $0(0,0 \%)$ & $8(100,0 \%)$ & $3(37,5 \%)$ & $5(62,5 \%)$ \\
\hline Espiritismo & & $4(66,7 \%)$ & $2(33,3 \%)$ & $1(16,7 \%)$ & $5(83,3 \%)$ \\
\hline Outras & & $1(50,0 \%)$ & $1(50,0 \%)$ & $1(50,0 \%)$ & $1(50,0 \%)$ \\
\hline
\end{tabular}

${ }^{1} \mathrm{p}$-valor do teste Qui-quadrado para comparação de proporção.

${ }^{2}$ p-valor do teste Exato de Fisher.

Fonte: Autores. 
Tabela 3. Distribuição do uso da força de caráter inteligência social, exercício da cidadania, segundo o perfil profissional dos professores avaliados.

\begin{tabular}{|c|c|c|c|c|}
\hline \multirow{3}{*}{ Fator avaliado } & \multicolumn{4}{|c|}{ As mais importantes } \\
\hline & \multicolumn{2}{|c|}{ Inteligência social } & \multicolumn{2}{|c|}{ Exercício da cidadania } \\
\hline & Sim & Não & Sim & Não \\
\hline \multicolumn{5}{|l|}{ Q7.Em quantas escolas você trabalha } \\
\hline Uma & $25(32,1 \%)$ & $53(67,9 \%)$ & $13(16,7 \%)$ & $65(83,3 \%)$ \\
\hline Duas & $2(50,0 \%)$ & $2(50,0 \%)$ & $2(50,0 \%)$ & $2(50,0 \%)$ \\
\hline p-valor & \multicolumn{2}{|r|}{$0,595^{2}$} & \multicolumn{2}{|c|}{$0,151^{2}$} \\
\hline \multicolumn{5}{|l|}{ Q8.Em quantas turmas você leciona } \\
\hline 1 a 2 & $5(38,5 \%)$ & $8(61,5 \%)$ & $0(0,0 \%)$ & $13(100, \%)$ \\
\hline 3 a 4 & $10(30,3 \%)$ & $23(69,7 \%)$ & $7(21,2 \%)$ & $26(78,8 \%)$ \\
\hline 5 a 6 & $8(33,3 \%)$ & $16(66,7 \%)$ & $5(20,8 \%)$ & $19(79,2 \%)$ \\
\hline 7 ou mais & $4(33,3 \%)$ & $8(66,7 \%)$ & $3(25,0 \%)$ & $9(75,0 \%)$ \\
\hline p-valor & \multicolumn{2}{|r|}{$0,973^{2}$} & \multicolumn{2}{|c|}{$0,280^{2}$} \\
\hline \multicolumn{5}{|l|}{ Q9.Em média, quantos alunos por turma } \\
\hline Menos de 30 alunos & $10(33,3 \%)$ & $20(66,7 \%)$ & $3(10,0 \%)$ & $27(90,0 \%)$ \\
\hline 30 alunos & $11(32,4 \%)$ & $23(67,6 \%)$ & $5(14,7 \%)$ & $29(85,3 \%)$ \\
\hline Acima de 30 alunos & $6(33,3 \%)$ & $12(66,7 \%)$ & $7(38,9 \%)$ & $11(61,1 \%)$ \\
\hline p-valor & \multicolumn{2}{|r|}{$0,996^{1}$} & \multicolumn{2}{|c|}{$0,034^{1}$} \\
\hline \multicolumn{5}{|l|}{ Q10. Em que níveis de ensino você leciona? } \\
\hline Fundamental & $0(0,0 \%)$ & $1(100,0 \%)$ & $1(100,0 \%)$ & $0(0,0 \%)$ \\
\hline Médio regular & $0(0,0 \%)$ & $1(100,0 \%)$ & $1(100,0 \%)$ & $0(0,0 \%)$ \\
\hline Médio Técnico & $24(32,9 \%)$ & $49(67,1 \%)$ & $13(17,8 \%)$ & $60(82,2 \%)$ \\
\hline Superior & $7(30,4 \%)$ & $16(69,6 \%)$ & $5(21,7 \%)$ & $18(78,3 \%)$ \\
\hline Pós-graduação & $1(100,0 \%)$ & $0(0,0 \%)$ & $0(0,0 \%)$ & $1(100,0 \%)$ \\
\hline p-valor & \multicolumn{2}{|r|}{$0,759^{2}$} & \multicolumn{2}{|c|}{$0,110^{2}$} \\
\hline \multicolumn{5}{|l|}{$\begin{array}{l}\text { Q11. Qual sua carga horária semanas de } \\
\text { trabalho? }\end{array}$} \\
\hline Menos de 40 horas semanais & $8(38,1 \%)$ & $13(61,9 \%)$ & $5(23,8 \%)$ & $16(76,2 \%)$ \\
\hline 40 horas semanais & $19(31,1 \%)$ & $42(68,9 \%)$ & $10(16,4 \%)$ & $51(83,6 \%)$ \\
\hline p-valor & \multicolumn{2}{|r|}{$0,559^{1}$} & \multicolumn{2}{|c|}{$0,516^{2}$} \\
\hline \multicolumn{5}{|l|}{$\begin{array}{l}\text { Q12. Você realiza atividades de trabalho em } \\
\text { outro local que não seja a escola? }\end{array}$} \\
\hline Sim & $17(39,5 \%)$ & $26(60,5 \%)$ & $10(23,3 \%)$ & $33(76,7 \%)$ \\
\hline Não & $10(25,6 \%)$ & $29(74,4 \%)$ & $5(12,8 \%)$ & $34(87,2 \%)$ \\
\hline p-valor & \multicolumn{2}{|r|}{$0,181^{1}$} & \multicolumn{2}{|c|}{$0,222^{1}$} \\
\hline \multicolumn{5}{|l|}{$\begin{array}{l}\text { Q13. Há quantos anos você exerce a } \\
\text { profissão de professor }\end{array}$} \\
\hline Até 5 anos & $6(31,6 \%)$ & $13(68,4 \%)$ & $5(26,3 \%)$ & $14(73,7 \%)$ \\
\hline 6 a 10 anos & $6(33,3 \%)$ & $12(66,7 \%)$ & $2(11,1 \%)$ & $16(88,9 \%)$ \\
\hline 11 a 20 anos & $6(24,0 \%)$ & $19(76,0 \%)$ & $4(16,0 \%)$ & $21(84,0 \%)$ \\
\hline Acima de 20 anos & $9(45,0 \%)$ & $11(55,0 \%)$ & $4(20,0 \%)$ & $16(80,0 \%)$ \\
\hline p-valor & & $0,524^{1}$ & & \\
\hline
\end{tabular}




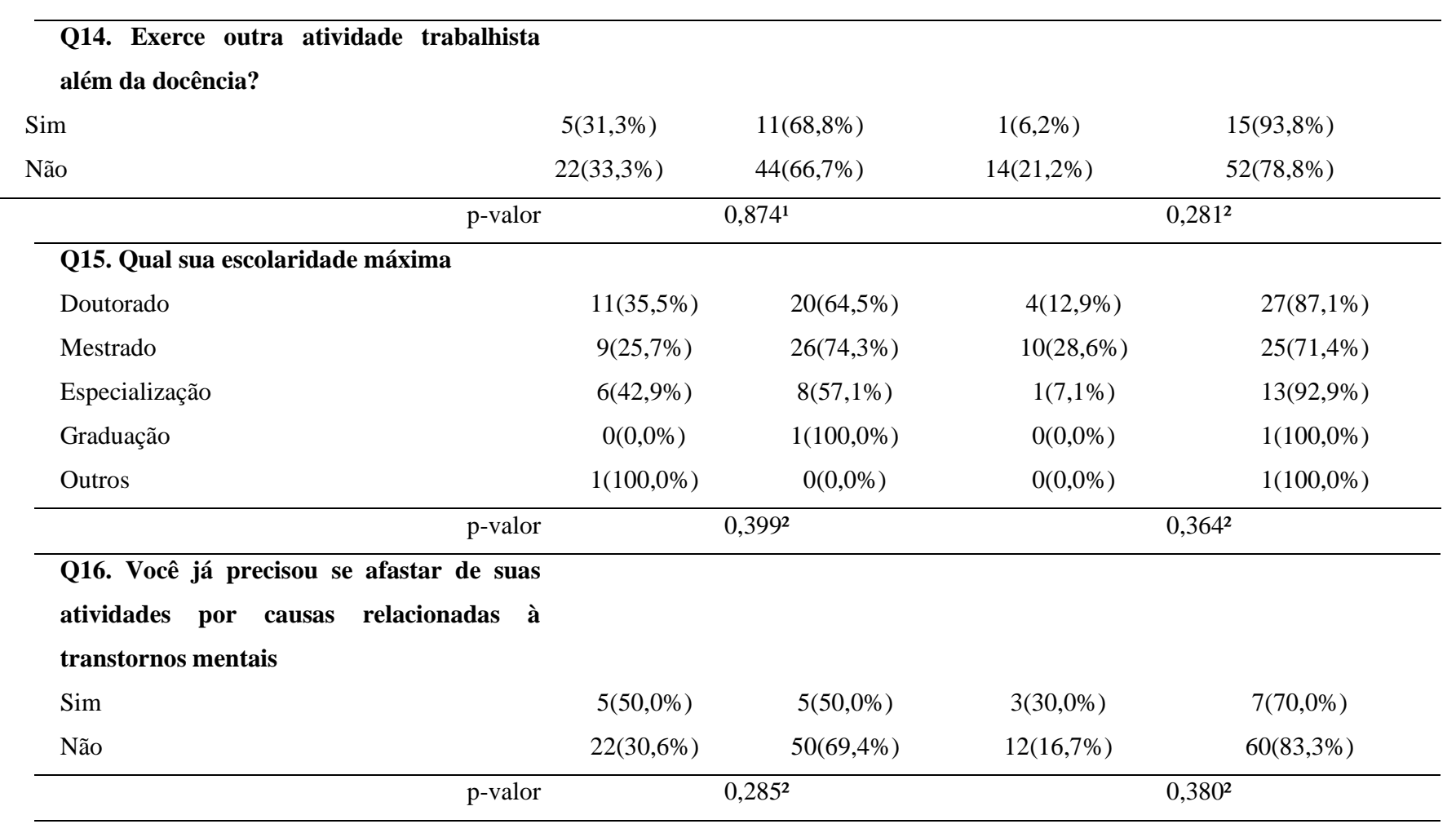

${ }^{1} \mathrm{p}$-valor do teste Qui-quadrado para comparação de proporção. ${ }^{2} \mathrm{p}$-valor do teste Exato de Fisher.

Fonte: Autores.

Neste estudo, verificou- se que, para a força de caráter inteligência social, houve influência significativa quanto a sua importância, apenas no aspecto sexo do professor $(\mathrm{p}$-valor $=0,008)$. No caso, o grupo do sexo feminino apresentou maior prevalência de importância para inteligência social (50,0\%).

Já, no que diz respeito a força de caráter exercício da cidadania, o único fator que influenciou significativamente na importância foi o número médio de alunos por turma ( $\mathrm{p}$-valor $=0,034)$. Portanto, professores que possuem turmas com mais de 30 alunos $(38,9 \%)$, apresentaram maior prevalência para importância dada ao exercício da cidadania na sua prática profissional.

\section{Discussão}

Estudo realizado por Pereira (2021) no campus Araranguá, do Instituto Federal de Ciência e Tecnologia de Santa Catarina, durante a pandemia COVID- 19, encontrou as seguinte perfil docente: 66,7\% dos professores eram do gênero masculino, 44,4\% do grupo pesquisado possui idade entre 40 e 50 anos, 74,1\% dos participantes eram mestres (mestrado acadêmico), 37\% responderam que lecionam entre 11 e 15 anos e 33,3\% dos professores lecionam na educação profissional entre 6 e 10 anos.

A partir dos achados do atual estudo, evidencia- se que, para os professores participantes, a inteligência social constitui- se ferramenta primordial para o exercício da docência. Associado a isso, é possível considerar que a virtude humanidade também foi elegida como mais importante para a prática docente. Para Gatti (2016), ser professor é uma das práticas profissionais de maior impacto no desenvolvimento humano, pois o processo educacional acontece por meio de relações humanas profundas.

Peterson e Seligman (2004) consideram que as inteligências quentes se dedicam à capacidade de raciocinar acerca das informações de relevância pessoal. Para eles, existem subtipos de inteligência, a inteligência emocional que relaciona a 
informação emocional com o raciocínio; inteligência pessoal, caracterizada pela autocompreensão e autoavaliação, capacidade de pensar sobre processos dinâmicos motivacionais e emocionais; e, por fim, a inteligência social, que se refere ao relacionamento com outras pessoas, incluindo as relações de confiança e persuasão.

Estudos retratam a relevância da aplicação desta força de caráter no contexto educacional. Segundo Huamán et al. (2020), existe uma correlação positiva entre a inteligência emocional do professor e a satisfação acadêmica do aluno, com destaque para o componente interpessoal (relacionamento interpessoal, responsabilidade social e empatia). Eles concluíram que a inteligência emocional do professor é importante para o processo educacional e para a interação professor-aluno.

De acordo com Kobarg (2020), as características de um professor com competência na área da inteligência emocional são a atenção para os sinais internos e para as emoções, bem como a capacidade de reconhecer como seus sentimentos os afetam e afetam o seu desempenho no trabalho. Pela perspectiva desse pesquisador, os educadores estão alertas quanto aos valores fundamentais e às melhores formas de agir, possuindo uma visão geral das situações diversas.

$\mathrm{O}$ ato de ensinar, por si, constitui- se uma prática social. Não apenas por concretizar a interação entre professores e aluno, mas também pelo fato de o professor refletir sua cultura e contextos sociais a que pertence. Portanto, a prática pedagógica do professor é influenciada pelo modo de pensar e agir diante das diversas facetas de sua vida (Machado, Santos \& Silva, 2019).

Desta maneira, verifica- se que o exercício docente é atravessado pelas relações estabelecidas pelo professor, considerando todas as motivações e emoções que envolvem essas interações sociais. Pela percepção dos docentes que participaram desta pesquisa, esta força de caráter se faz necessária para propiciar um desempenho satisfatório no trabalho que, por conseguinte, proporcionará um ambiente de aprendizagem de excelência para o aluno.

Ademais, o presente estudo identificou que de maneira significativa, entre as professoras, para exercer a docência, a habilidade humana mais importante é a inteligência social. Dornelles e Crispim (2021) constataram que mesmo diante das relação significativas entre o gênero e a inteligência emocional não é possível concluir diferenças, devido a diversidade de resultados encontrados na literatura.

Em se tratando da virtude Humanidade, outra força de caráter citada pelos professores foi o amor. O amor é entendido aqui como a valorização das relações próximas com outras pessoas, especialmente entre aquelas com quem há um compartilhamento de sentimentos e um cuidado, que acontecem de forma recíproca entre os envolvidos (Peterson \& Seligman, 2004).

O processo de aprendizagem acontece por meio da interação com o outro, portanto ele não depende, exclusivamente, do âmbito cognitivo, é também afeto. $\mathrm{O}$ amor precisa estar envolvido em todo este processo, bem como o afeto, um toque, uma palavra de estímulo, carinho, respeito. Estes sentimentos são necessários para que ocorra a aprendizagem significativa. Portanto, todos esses aspectos devem ser uma conquista cotidiana que professor e aluno precisam construir juntos, para que ocorra uma aprendizagem eficaz (Madruga, 2020).

Outra força de caráter, expressivamente, citada como importante para a prática docente foi o exercício da cidadania que, por sua vez, está relacionada à virtude justiça. Em se tratando do âmbito da psicologia positiva, esta força de caráter abrange três outros conceitos, reponsabilidade social, lealdade e trabalho em equipe.

Neste caso, a cidadania é entendida como um senso de responsabilidade, voltada para o bem comum que inclui a si mesmo, mas se estende além dos próprios interesses para incluir os grupos dos quais fazem parte - família, trabalho, vizinhança ou mesmo todas as pessoas (Peterson \& Seligman, 2004).

Partindo desse conceito, observa- se que o professores participantes deste estudo compreendem que o exercício da docência é algo intrínseco à cidadania, pois sua prática profissional pode contribuir diretamente para o bem comum, que alcança não apenas aqueles alunos em sala de aula, mas seus familiares e a comunidade em que está inserido. 
Frise-se que esta força de caráter pode ser exercitada tanto com atividades de ensino, quanto com trabalhos de pesquisa e extensão. Porquanto, a partir delas, os educadores alcançam outras pessoas e colaboram não apenas com a grupo escolar, mas também com a comunidade em geral.

Para Masetto (2020), entre as competências apresentadas pelo professor, está a dimensão política e cidadã. Este campo da docência diz respeito ao estimulo para a formação profissional dos estudantes, imbuídos no interesse de formar pessoas com ética e responsabilidade social em suas decisões profissionais.

E mais, para alcançar o desenvolvimento da sociedade da qual eles fazem parte. Segundo o mesmo autor, os projetos pedagógicos exigem novas competências, entre elas, o saber trabalhar colaborativamente em equipe com seus pares.

'Faz-se necessário destacar que, no presente estudo, docentes com mais de 30 estudantes por turmas, consideram significativamente, como mais importante para sua prática escolar, o exercício da cidadania. Possivelmente estes professores estão vinculados a disciplinas propedêuticas e possuem formação didático- pedagógica, como também consideram como primordial para o seu trabalho os princípios basilares da instituição de ensino em questão, como a equidade e justiça social.

Para Alves, Nascimento e Saraiva (2017) pensar a formação de professores no contexto atual envolve um esforço de reflexão contextualizada, com ênfase nas conjunturas das diferentes escalas e agentes sociais envolvidos no processo de ensino e aprendizagem

Outra perspectiva apresentada, é o professor como um líder. Considerando o educador como sujeito de liderança na escola, sua capacidade de promover o crescimento pessoal e social do aluno é evidenciada pela concretização de uma liderança para aprendizagem, equidade e justiça social. No entanto, nada disso poderá ser efetivado sem o compromisso pessoal do professor em desenvolver essas ferramentas. (Antunes \& Silva, 2015).

Cidadania, equidade e liderança compõem a virtude da justiça, portanto, a relevância desta virtude para os professores em questão, pode ser evidenciada pelo fato de todas as forças que a compõem terem sido citadas neste estudo. Portanto, verifica- se que, do ponto de vista dos professores participantes a educação, prática elementar do docente, é intrínseca ao exercício da justiça.

Outro resultado encontrado nesta pesquisa foi a importância do amor pela aprendizagem. Nesse sentido, acrescenta- se a necessidade constante do aperfeiçoamento docente tanto para sua prática pedagógica, quanto para a atualização dos conteúdos específicos da sua área de conhecimento.

O exercício desta força de caráter é elementar na docência, o amor pela busca do conhecimento contribui para melhores práticas profissionais e, consequentemente, com o processo de ensino- aprendizagem. De acordo com Madruga (2020), para que o professor ensine bem é primordial que haja uma atualização constante, considerando que o docente ensina ao tempo em que aprende.

O amor pela busca do conhecimento está inserido na virtude da sabedoria, bem como as forças de caráter, também citada pelos professores, criatividade, curiosidade e mente aberta. Verifica-se, portanto, que praticamente todas elas foram contempladas, excetuando- se a perspectiva.

Neste caso, partindo dos conceitos apresentados por Seligman e Peterson (2004), os participantes deste estudo consideram que, para o trabalho docente, é importante que o professor reflita sobre novas maneiras de realizar as coisas, produzir ideias ou comportamentos, pensar sobre os acontecimentos e analisá-los de todos os ângulos, de maneira a não se tomarem conclusões precipitadas. E, além disto, é relevante que o professor tenha o gosto por explorar e descobrir; buscar novas experiências.

De acordo com Ghedin, Maciel e Silva (2021) com a formação docente, na conjuntura das licenciaturas, precisa- se incorporar parâmetros, tais como a promoção do comportamento autônomo, criativo, crítico e reflexivo, oriundos de um posicionamento de investigador em face da prática profissional docente. 
Estudos mostram que a curiosidade é um elemento destacado por pessoas que têm interesse na docência, constituindo um fator motivador para escolha da licenciatura em história, por exemplo (Souza \& Ramos, 2019).

Com relação ao senso crítico, as relações estabelecidas pelos professores no contexto escolar exigem uma constante avaliação dos processos interpessoais, de maneira que todas as suas ações devem ser ponderadas por todos os ângulos.

De acordo com Freire (2007, p.19) "O professor precisa ser um aprendiz ativo e cético na sala de aula, que convida os alunos a serem curiosos e críticos... e criativos". No entanto, para que o docente instigue estas forças de caráter em seus estudantes, faz- se necessário que ele também exercite estas práticas.

Outras características consideradas importantes para a atividade destes profissionais são a integridade e persistência, forças de caráter relacionadas à virtude coragem. Neste âmbito, Freire (1996) faz um chamamento, considerando a responsabilidade moral dos educadores em sua prática profissional. Para ele, o preparo científico docente deve estar equiparado com sua retidão ética.

Em sua obra "Pedagogia da autonomia: saberes necessários à prática profissional", Freire (1996) destaca que formação acadêmica, retidão ética, respeito ao próximo, coerência, capacidade de viver e aprender com o diferente, não interferência de problemas pessoais ou antipatia com relação ao outros, constituem uma obrigatoriedade a que, humildemente, os educadores devem se dedicar a alcançar de maneira perseverante.

Deste modo, percebe- se que, no contexto educacional, é primordial que os professores assumam um compromisso com a honestidade em todas as suas práticas. Além disso, devem utilizar-se da ferramenta da persistência a fim de manterem-se motivados a traçar e alcançar metas estabelecidas.

Por fim, os participantes da pesquisa destacaram as forças de caráter esperança e humildade, que estão relacionadas, respectivamente, às virtudes transcendência e temperança.

Para Freire (1997), o ato de ensinar exige que os professores tornem- se cada vez mais tolerantes, cada vez mais transparentes, transformando- se gradativamente em críticos, e fazendo- se na mesma proporção mais curiosos. E, neste ponto, quanto mais tolerantes, transparentes, críticos, humildes, mais se aproximam, autenticamente, da prática docente. Ensinar exige o cultivo da humildade e da tolerância, pois o educador precisa respeitar a curiosidade e a timidez de seus alunos, para que suas práticas não os inibam (Freire, 1996).

No campo da educação a esperança é necessidade ontológica. No entanto, sozinha, não é suficiente para transformação do mundo. Pensar, deste modo ingênuo, é cair na desesperança, no pessimismo. Então, por ser necessidade ontológica, esta força de caráter precisa estar ancorada na prática. Logo, é tarefa do educador desvelar as possibilidades da esperança, fundamentada na análise política, pois, sem ela, pouco poderá ser feito, o embate nem poderá ser iniciado (Freire, 1997).

\section{Considerações Finais}

Este estudo apresentou as forças de caráter consideradas mais importantes para o exercício da prática docente. Destaca- se entre os seus resultados que, a partir das forças de caráter citadas pelos participantes da pesquisa, todas as virtudes foram contempladas, portanto, para o público-alvo, todas as virtudes devem ser consideradas para o trabalho do professor.

Verificou- se que, expressivamente, a força de caráter mais citada foi a inteligência social, o que permite inferir que, para os professores participantes, as relações sociais e emocionais estabelecidas pelos docentes são a ferramenta mais importante para sua prática profissional.

Por conseguinte, observa- se que a atividade do educador é envolvida pelos afetos, pelas relações humanas, pelo estabelecimento de elos entre os sujeitos envolvidos no processo educacional. 
Outro resultado que cabe ser destacado foi a importância do exercício da cidadania para os profissionais em questão. Neste contexto, percebeu- se que todas as forças de caráter que são envolvidas pela virtude justiça foram citadas. Deste modo, acrescenta- se que, para esses docentes, o exercício da sua profissão está diretamente relacionado ao senso de liderança, responsabilidade e justiça social, equidade e necessidade do trabalho em equipe.

Por fim, os achados deste estudo, mostram que, a partir da perspectiva do professor, o exercício da inteligência social, cidadania, amor por aprender, criatividade, amor, integridade, senso crítico, esperança, persistência, curiosidade, equidade, humildade e liderança, colaboram de maneira considerável para a sua prática profissional.

Salienta- se que esta pesquisa não buscou verificar se, ao considerar que essas ferramentas são importantes, os professores também buscam formas de desenvolver essas forças. Outra limitação deste estudo foi o não aprofundamento da investigação, ao ponto de conhecer em que proporção essas ferramentas são utilizadas no exercício da prática docente e de que forma elas podem ser executadas no cotidiano desses professores.

A partir desta investigação, mostra- se necessária a inclusão de programas de aperfeiçoamento profissional, que consideram atividades fundamentadas no exercício das forças de caráter de professores, no contexto dos trabalhadores participantes desta pesquisa. Por meio dessas práticas, será possível proporcionar um ambiente de trabalho favorável ao desenvolvimento do processo de ensino- aprendizagem.

Diante da relevância da representação social da educação, sugere- se a realização de outras pesquisas na área dos constructos da psicologia positiva no contexto escolar. As pesquisas que investigam a apropriação de forças de caráter de professores são necessárias, tanto para o aprimoramento da sua prática profissional, quanto para contribuir com o seu bemestar subjetivo.

\section{Referências}

Alves, P. D. S., do Nascimento, F. S., \& Saraiva, L. A. P. (2017). Reflexões Sobre A Formação Do Professor De Geografia: caminhos para o ensino da cidadania. Anais COPRECIS. Realize Editora. https://www.editorarealize.com.br/index.php/artigo/visualizar/31592

Antunes, R. R., \& Silva, A. P. (2015). A Liderança dos Professores para a Equidade e a Aprendizagem. Revista Lusófona de Educação, 30(30), 73-97. https://revistas.ulusofona.pt/index.php/rleducacao/article/view/5130

Cacciari, M. B. (2015). Emprego ou vocação? Correlatos do bem-estar em professores universitários. Dissertação de Mestrado. Programa de Pós-Graduação em Psicologia, Universidade Federal do Espírito Santo, Vitória, ES. http://repositorio.ufes.br/handle/10/9040

Cintra, C. L. (2016). Educação positiva: satisfação com o trabalho, forças de caráter e bem-estar psicológico de professores escolares. Dissertação de Mestrado. Programa de Pós-Graduação em Psicologia, Universidade Federal do Espírito Santo, Vitória, ES. https://repositorio.ufes.br/handle/10/9054

Dornelles, M., \& Crispim, S. F. (2021). Inteligência emocional de professores universitários: um estudo comparativo entre ensino público e privado no Brasil. Revista Internacional de Educação Superior, 7, e021016-e021016. https://doi.org/10.20396/riesup.v7i0.8657189

Souza, T. R. B., \& Ramos, K. M. C. (2019) Profissionalização docente: elementos que mobilizaram a escolha de estudantes (futuros professores) pelo curso de Licenciatura em História. Revista FAFIRE, 12, (2), 33-39. https://dx.doi.org/10.24024/23585188n12n2a2019p33039

Ferreira, M. M. (2018). Os benefícios da Psicologia Positiva para a Educação Básica. Revista Especialize On-line IPOG (15a ed.), https://assets.ipog.edu.br/wp-content/uploads/2019/12/07013918/marcela-martins-ferreira-fdgyn002-1281531.pdf

Freire, P (1997). Pedagogia da esperança: um encontro com a pedagogia do oprimido. Paz e Terra.

Freire, P. (1996). Pedagogia da autonomia: saberes necessários à prática educativa. Paz e Terra.

Freire, P. (2007) Educação e mudança (30a ed). Paz e Terra.

Gaspar, T., Tomé, G., Ramiro, L., Almeida, A., \& Matos, M. G. D. (2020). Ecossistemas de aprendizagem e bem-estar: factores que influenciam o sucesso escolar. Psicologia, Saúde and Doenças, 21(02), 462-481. http://dx.doi.org/10.15309/20psd210221

Gatti, B. A. (2016). Formação de professores: condições e problemas atuais. Revista internacional de formação de professores, 1(2), 161-171. https://periodicos.itp.ifsp.edu.br/index.php/RIFP/article/view/347/360

Ghedin, E. L., Maciel, C. C. M., \& da Silva, A. M. (2021). Didática e formação inicial do professor: desafios e perspectivas na visão dos acadêmicos do curso de pedagogia de uma Instituição de Ensino Superior (IES) do município de Parintins-AM. Revista Ibero-Americana de Estudos em Educação, 881-895. https://doi.org/10.21723/riaee.v16iEsp.1.14923 
Research, Society and Development, v. 10, n. 7, e8610716408, 2021

(CC BY 4.0) | ISSN 2525-3409 | DOI: http://dx.doi.org/10.33448/rsd-v10i7.16408

Kobarg, A. P. R. (2020). Um professor mais feliz: O poder da inteligência emocional. Insular Livros.

Machado, G. C., dos Santos, A. M., \& da Silva, R. S. (2020). Trabalho docente: reflexões sobre a saúde e o sofrimento psíquico do professor. Revista Prâksis, 1, 16-30. https://doi.org/10.25112/rpr.v1i0.2034

Madruga, R. D. S. (2020). O vínculo afetivo entre professor e aluno: Um elemento facilitador para aprendizagem significativa. Brazilian Journal of Development, 6(9), 69716-69736. https://doi.org/10.34117/bjdv6n9-426

Masetto, M. T. (2020). Exercer a docência no Ensino Superior Brasileiro na contemporaneidade com sucesso (competência e eficácia) apresenta como um grande desafio para o professor universitário. Revista Diálogo Educacional, 20(65). http://dx.doi.org/10.7213/1981-416X.20.065.DS15

Oliveira, S. (2021). Contribuições da Psicologia Positiva: bem-estar e promoção da saúde física e mental para pessoas com 50+ e idosos. Revista Longeviver. https://revistalongeviver.com.br/index.php/revistaportal/article/viewFile/893/956

Oliveira, C., Nunes, M. F. O., Legal, E. J., \& Noronha, A. P. P. (2016). Bem-Estar Subjetivo: estudo de correlação com as Forças de Caráter. Avaliaçao Psicologica: Interamerican Journal of Psychological Assessment, 15(2), 177-185. https://doi.org/10.15689/ap.2016.1502.06

Paludo, S.D.S e Koller, S.H. (2007). Psicologia Positiva: uma nova abordagem para questões antigas. Paidéia (Ribeirão Preto), 17 (36), 9-20. https://doi.org/10.1590/S0103-863X2007000100002

Park, N., Peterson, C., \& Seligman, M. E. P. (2004). Strengths of character and well-being. Journal of Social and Clinical Psychology, 23(5), 603-619. https://doi.org/10.1521/jscp.23.5.603.50748

Pereira, E. L. (2021). Práticas docentes nos cursos técnicos integrados do campus Araranguá do IFSC durante a pandemia COVID-19. Trabalho de Conclusão de Curso de Especialização. Curso de Especialização em Educação Científica e Matemática, Instituto Federal de Educação, Ciência e Tecnologia de Santa Catarina. https://repositorio.ifsc.edu.br/handle/123456789/1976

Peterson, C., \& Seligman, M. E. P. (2004). Character strengths and virtues: A handbook and classification. Oxford University Press.

Ribeiro, A. F. (2018). Desenvolvimento de forças de caráter em estudantes do ensino fundamental: uma proposta de intervenção. Dissertação de Mestrado. Programa de Pós- Graduação em Educação, Universidade do Oeste Paulista, Presidente Prudente, SP. http://bdtd.unoeste.br:8080/jspui/handle/jspui/1146

Seligman, M. E. (2019). Felicidade autêntica (Nova edição): Use a psicologia positiva para alcançar todo seu potencial. Objetiva.

Seligman, M. E. P., \& Csikszentmihalyi, M. (2000). Positive psychology: an introduction. American Psychologist, 55 (1),5-14. https://doi.org/10.1037//0003066X.55.1.5

Tomé, G., Matos, M. G., Gomes, P., Camacho, I., \& Gaspar, T. (2017). Promoção da saúde mental nas escolas - Projeto ES’COOL. Revista de Psicologia da Criança e do Adolescente, 8(1), 173- 184. https://doi.org/10.34628/rhaq-3f06 